\title{
Writing and Translating Research Papers in English: Discourse Community, Academic and Specific English Programs towards European Complied Programs and Research Papers
}

\author{
Bardha Gashi, Msc.
}

University "Haxhi Zeka"- Peja, Kosovo

bardha.gashi@unhz.eu

Doi:10.5901/ajis.2015.v4n2s1p38

\begin{abstract}
This research paper intends to bring out a clarification of English used for academic purposes and the role of it in scientific research. Nowadays, English is an international endeavor of many fields of study; therefore, this paper investigates various international models in use and offers a model which is applicable to practical situations and settings, such as the teaching of English for Academic Purposes within research settings. Since English is the major communication and research language, the ability to write research papers in English is a major goal of tertiary education and it is the focal point of the researchers of different fields of study. Particularly, the research explores genre analysis that adds the understanding of how language is used within a specific situation and setting. Respectively, this research investigates the analysis of academic English writing/research papers and the impact of the direct translation and language transfer from L1 to L2. Hence, many research papers have been analyzed based on the English for academic purposes criteria and, the transmitting of the correct massage by not using direct translation. Finally, in this paper has been clarified the use of English in academic and research setting. The analysis of the translated research papers in English shows that regarding the issue of academic English remains a gap for further development and improvement. By exploring and explaining the role of English in research and the analysis of genres, discourse community and academic English, this study offers models and practices compiled to European standards criteria of proper use of English in research setting and academic writing.
\end{abstract}

Keywords: Academic and research English programs, genre analysis, discourse community, direct translation and language transfer, research paper analysis.

\section{Introduction}

Generally, the role of English in research is immense considering the fact that the language of the conferences and journals is predominantly English. But, the focus is not only on the direct message transmitted word by word, because the understanding and comprehension of the text idles away. So far, in Kosovo's public universities, many conferences have been organized as well as a considerable amount of research papers have been published, all of these in English and some of them include an impact factor. Yet, almost no researches have been done to study the ways of translating such papers from Albanian to English language. Hence, the main aim of this paper is to bring out and highlight some of the issues concerning English in an academic setting in Kosovo, defined as a language that is used in different contexts and fields of research. Also, another focal point is the translation and adaption of the texts.

As regards to discourse community, "discourse analysis deals with the study of the ways in which language is used in texts and contexts." Developed in the 1970s, the discourse analysis "concerns itself with the use of language in a running discourse, continued over a number of sentences, and involving the interaction of speaker (or writer) and auditor (or reader) in a specific situational context, and within a framework of social and cultural conventions" (Abrams, M.H., \&Harpham, G.G.). While this research paper elaborates writing in an academic setting should be defined the way how the language is used and the translation is adapted to the context.

Additionally, in 1990 a publication by Swales has been to play a leading role in linking language learning and discourse, particularly in the research and academic context. Also, in the definitions of the characteristics ofdiscourse community noted by Swales include "participatory mechanisms of intercommunication, mastery of a specific lexis, and the use of one or more genres. "More importantly, he definesthe discourse community as "a threshold level of members with a suitable degree of relevant content and discoursal expertise" (Swales 1990, p. 27).

While, the analyzed journals include papers from various academic settings and fields of study, have been involved 
more than one genre and diverse levels of interpretation and intercommunication. In order to identify such points properly, a professional translation is more than necessary.

According to Hyland (2003), "genre is a term for grouping text together, representing how writers typically use language to respond to recurring situations." Hence, the role of translators and editors in such cases is not only to use the words, but to transmit the message by regarding the situations and specific academic contexts. Regarding genre analysis, more importantly, in the genre of research articles, the understanding should be adjusted by following the steps as in the CARS Model defined by Swales, J. (1990). This model include some guiding steps that facilitate understanding of the texts and give writers some moves that direct them to a comprehensive writing.

Moreover, related to reading and comprehension of the research papers, a study by Huckin as cited in (Swales, J. 1990, p.15)noted that:

\begin{abstract}
When I asked them to demonstrate how they customarily read a newly-published article in the field, they all displayed a reading pattern dominated by the search of new information. First they read the title, then the abstract, then they looked for most important data, usually in graphs, tables, drawings and other visual aids. Next, they typically read the Results section. At this point, their reading pattern varied, depending on how well they knew the topic and how confident they were of the scientific methods used.
\end{abstract}

As the participants in the study of Huckin seek out for information while reading different articles, translation is a way to reveal and highlight effectively that information to the reader.Furthermore, writing and translating are directly related to understanding of meaning. If the translated version fails to transmit the message, even though, the research has a great importance it lacks the validation. This can be explained comparing that to an expert who has a great deal of background knowledge, but fails, when it comes to transmitting it to the audience. Hence, it depends on the writer or translator to bring to light the proper message, otherwise, the main part of the writing remains on the head of the writer.

As mentioned above on, regarding the conceptualization of discourse community, (Swales, J. 1990, pp. 471- 472) proposed six characteristics that are necessary and sufficient to identify a group of individuals as a discourse community:

A discourse community has a broadly agreed set of common public goals; 2. A discourse community has mechanisms of intercommunication among its members; 3 . A discourse community uses its participatory mechanisms primarily to provide information and feedback; 4 . A discourse community utilizes and hence possesses one or more genres in the communicative furtherance of its aims; 5 . In addition to owning genres, a discourse community has acquired some specific lexis; 6 . A discourse community has a threshold level of members with a suitable degree of relevant content and discoursal expertise.

Understanding the sixth characteristics of discourse community may increase the validation of the translation or may serve as benchmarks in a research.

Another focal point is translation methods that have a great impact on the research papers. Lately, back-translation method is considered as an effective wayto use rather than direct translation. Based on the analyzed papers, many of the papers have been directly translated from Albanian to English, and some of them have been written directly in English without the mediation of the translation. Obviously, the texts that were written in English by the researchers who know such contexts and their field of study, thus, give a particular effect on the readers' comprehension. Whereas, the research papers that have been translated from Albanian into English remains incomplete in the terms of comprehension. This happens because of the lack of knowing the context of the study and also the academic or specific vocabulary that should be used properly depending on the field of study.

Finally, there are many European models and frameworks available to facilitate writing a scientific paper in English. The most recent book that was updated by "European Commission Directorate-General for Translation called "English Style Guide" (A handbook for authors and translators in the European Commission, 2015) is intended primarily for English-language authors and translators, both in-house and freelance, working for the European Commission. But now that so many texts in and around the EU institutions are drafted in English by native and non-native speakers alike, its rules, reminders and handy references aim to serve a wider readership as well." (p. 1) Therefore, the book provides a standardized criterion for using English in the research and academic setting. It includes many language and linguistics issues that are practical and could be a proper guide towards European standardized research papers and academic writing framework.

\title{
2. Research Methodology
}

In order to compile the data for this research, fifteen scientific journals have been analyzed. All the research papers that 
have been published are from the conferences of the main public Universities in Kosovo from 2010 to 2014. This research is mainly analytical, where, have been analyzed the translated research papers from Albanian to English. The main focus has been on: genre analysis, discourse community and context, direct translation and language transfer L1 to L2 and appropriate academic vocabulary used. It has been included the secondary data and all the sources and research papers used are published.

\section{Research Findings and Discussion}

The results of the analyzed data have proved that there is a gap when it comes to writing or translating a research paper in English. Based on the collected data from the scientific journals of public universities in Kosovo, most of the papers lack the real transmitted message and the text remains incomplete and in some cases ambiguous. From a semantic viewpoint the concepts of a research underlying the L1 constitute a source of transfer that could be 'transferring ideas to nowhere' or 'transferring ideas to somewhere'. That could be explained as transferring the main points properly from L1 to $L 2$, or transferring a vague text that directs to hiding research importance. Hence, language is a key factor in a research setting and has a powerful impact on the convenient translation and content. The avoidance of using a translation machine or online translation program immediately would increase the translation quality in research. Respectively, professionals are knowledgeable and familiar with the translation process, particularly, identifying genre analysis and the academic context in which the research is taking place. But, the researchers should be aware of the difference between general English and English used for academic and research purposes. Based on the data, the conference participants do not receive any feedback or critical appraisal after sending the full papers. That hinders the improvement of researching quality in general and specifically the English version of the papers. Hence, a feedback overview is a 'must' regarding research papers before the publication.

Table 1. The use of specific academic English within a research setting by including genre analysis, discourse community and language transfer.

\begin{tabular}{|l|l|l|}
\hline Language Transfer L1 to L2 & Genre Analysis & Discourse Community \& Context \\
\hline $\begin{array}{l}\text { In a majority of the research papers (75\%) have been } \\
\text { used a direct translation or literal translation instead } \\
\text { of a back translation technique. The language } \\
\text { transfer has been made directly from L1 to L2 by } \\
\text { interfering in the meaning and comprehension. }\end{array}$ & $\begin{array}{l}\text { Renre of English for Academic purposes, in } \\
\text { many of the papers academic vocabulary }\end{array}$ & $\begin{array}{l}\text { Organized groups to foster intercommunication in } \\
\text { vacademic contexts. The researchers are } \\
\text { not terms hardly havedgeable enough to identify discourse } \\
\text { community and its importance in research setting. }\end{array}$ \\
\hline
\end{tabular}

Furthermore, the opportunity of Kosovar researchers to publish papers in international research setting and conferences is increasing more and more nowadays. Yet, from the data collected and analyzed, it could be claimed that many texts translated from Albanian to English have a vague meaning, what hinders identifying the understanding and how language is used within a specific situation. The importance of the clear content should be highlighted in the research papers rather than using literal translation.

To conclude, what most hinders the process of conveying a research paper message to English is the lack of Academic English knowledge.

\section{Conclusions and Recommendations}

To conclude, there are many issues that should be raised and expanded regarding English in an academic and research setting. Despite the fact that many of the participants in such conferences have a PhD degree or at least an MA degree, it does not mean that, they do not need feedback of their work. One could be a great researcher and expert on a field as well, but, not all have the competency and the professional sight to put the ideas on the white paper. Based on the analyzed research papers and journals that have been organized by public universities in Kosovo so far, the lack of sending feedback after receiving the full papers is obvious. All the papers included in such journals need a close professional eyesight and checking, considering the fact that the researches are done using various genres and in diverse discourse communities as well as different academic contexts, even though, the researchers are professionals in their field of study. More importantly, to avoid unnecessary and continuous language and applied linguistics errors, that should be an appropriate way to enhance English writing in an academic setting. Except sending feedback, in such cases could be started by organizing training and courses related to English used in academic and specific contexts. Besides 
that, training of the academic staff in the field of academic writing and orthography courses would be useful. Also, it should be emphasized the importance of ESP or EAP during the first cycle studies, that currently is at the inception stage at the public universities in Kosovo. In order to have idiosyncrasy in the translated research paper is needed a committee of bilinguals and professional translators.

On the other hand,due to the lack of first data, this study should be expanded by a comparison between the first and the second data. To avoiddiscrepancy, a demonstrating group of translators that deal with scientific papers translation, and researchers who write their papers directly in English would be more than necessary to be included in this study.

Finally, the findings of this research paper based on the facts of the second data, offers a clear description and some hints of the English writing and translating in an academic setting and its lacks and shortcomings, by providing recommendations for further improvement of English within the academic context towards European standards criteria of proper use of English in research setting and academic writing. There is much to be done in enhancing the quality of scientific journals, particularly, working on the translation process by avoiding non-professional or literal translation and increasing the use of academic English in the research setting.

\section{References}

Bjöorn, H. J. (1993). Review of John M. Swales 'Genre Analysis: English in Academic and Research Settings' Studies in Second Language Acquisition, 15, pp 125-126.

Desiree, M. R (1994). Review of Vijay K. Bhatia 'ANALYSING GENRE: LANGUAGE USE IN PROFESSIONAL SETTINGS' Studies in Second Language Acquisition, 16, pp 502-503.

European Commission Directorate-General for Translation, English Style Guide, A handbook for authors and translators in the European Commission, Seventh edition: August 2011 Last updated: May 2015

Hek, G. Judd, M.Moule, P. (2002) Making Sense of Research. An introduction for health and social care practitioners. 2nd Edition. London : Continuum

Hyland, K. 2003. Second language writing. New York: Cambridge University Press.

Swales, J. (1990) Genre analysis: English in academic and research settings. Cambridge: Cambridge University Press

Swales, J. (1990) The Concept of Discourse Community, the Concept of Discourse Community Genre Analysis: English in Academic and Research Settings. Boston: Cambridge UP, 1990. pp, 21-32.

http://www.sp.uconn.edu/ jblo0001/swales_cars_introductions_model.htm 